\title{
Quadriceps tendon tear rupture in healthy patients treated with patellar drilling holes: clinical and ultrasonographic analysis after 36 months of follow-up
}

\author{
Michele Arcangelo Verdano \\ Matteo Zanelli \\ Davide Aliani \\ Tiziana Corsini \\ Andrea Pellegrini \\ Francesco Ceccarelli
}

Orthopaedic Department, University of Parma, Italy

Corresponding author:

Davide Aliani

Orthopaedic Department, University of Parma

Via Gramsci, 14

43120 Parma, Italy

E-mail: davide.aliani@gmail.com

\section{Summary}

Background: quadriceps tendon subcutaneous rupture is an uncommon injury affecting predominantly middle-aged men as a result of direct or indirect trauma; aim of this work is to evaluate clinical outcome and tendon morphology in patients treated surgically with transpatellar drilling suture. Methods: 20 patients (20 male) with an average age of 54 (42-59) were evaluated with a mean follow-up of 36 months.

Measurements of range of motion (ROM) and of tight circumference were collected. Lysholm and Rougraff Score were also performed.

All the patients underwent a US evaluation the morphologic changes of the repaired tendon.

Results: mean active ROM was $1^{\circ}-117^{\circ}$; average difference in the circumference of the quadriceps was $2.6 \% 10 \mathrm{C}$ and $3.3 \% 15 \mathrm{C}$. The mean Lysholm Score calculated was $88 / 100$; the mean Rougraff Score $17 / 25$.

At ultrasonographic evaluation all tendons were continuous; heterotopic ossification was present in 18 quadriceps tendons. Thickness was augmented in 18 quadriceps tendons and in 5 patellar tendons. Vascularization was always conserved. Lateral subluxation of patella was reported in 1 case.

Conclusions: patellar drilling holes repair is a nondemanding procedure, inexpensive and technically uncomplicated.

US evaluation confirms tendon healing; tendon remodeling does not affect patient's clinical outcome and quality of life.

Level of incidence: IV
KEY WORDS: Patellar drilling holes, quadriceps, tendon rupture, ultrasound.

\section{Introduction}

Quadriceps tendon rupture is an uncommon injury with an incidence of $1.37 / 100,000$ patients per year ${ }^{1}$. Men are more frequently affected than women (M: $\mathrm{F}$ $=4.2: 1$ ), and the mean age is around 50 years old ${ }^{1}$. Fatty and cystic degeneration of tendons, mixed degeneration, microangioblastic dysplasia, decrease in collagen and calcification occurs naturally with aging ${ }^{2}$ but while these structural changes weaken the structural stability of the tendon, rarely spontaneous rupture is observed even in the elderly ${ }^{3}$.

Most commonly this injury is the result of direct or indirect trauma. A violent eccentric contraction is the most frequent cause of quadriceps tear rupture ${ }^{4}$. Spontaneous ruptures, even sometimes bilaterally, have been reported in people with predisposing conditions such as chronic renal failure, rheumatoid arthritis, diabetes, gout and steroids abuse ${ }^{5}$ or quinolone antibiotics use ${ }^{6}$.

The patient often describes the traumatic mechanism as a traumatic event while the limb is in hyperextension, followed by a sharp pain in the anterior side of the tight and absolute inability to actively extend the affected knee. Pain is sudden and severe. Testing the knee extended relieves the pain.

At the physical examination a gap in the suprapatellar zone is palpable and effusion might be present. Despite all these obvious signs and symptoms, the rupture of quadriceps tear may be missed. The radiological procedures for the diagnosis are direct radiography, ultrasound (US) and magnetic resonance imaging $(\mathrm{MRI})^{7}$. The sensitivity of US in determining the localization of the rupture is high. It is also quite sensitive in differentiating complete by partial ruptures. $\mathrm{MRI}$ is the most effective imaging method ${ }^{8}$.

In our series of cases we repaired the lesion with transpatellar drilling suture; we re-evaluated active patients (less than 60 years old and without important comorbidities) with physical examination, functional scores, and US in order to study the effectiveness of this surgical technique and the post-operative recover in this population.

Aim of this work is to study the clinical outcome of a series of quadriceps tendon repaired with patellar drilling holes, and to compare it with Literature. This is the first clinical study evaluating the ultrasono- 
Quadriceps tendon tear rupture in healthy patients treated with patellar drilling holes: clinical and ultrasonographic analysis after 36 months of follow-up

graphic changes in the morphology of quadriceps tendon surgically repaired.

\section{Materials and methods}

In our study we evaluated 20 patients (20 male) treated in our Institute after the subcutaneous traumatic rupture of the quadriceps tendon from January 2009 to January 2011 with a mean follow-up of 36 months. Data were prospectively collected and retrospectively analyzed.

In this study were included all the patients treated with transpatellar drilling repair after acute quadriceps tear rupture, younger than 60 years. Patients with important comorbidities predisposing to rupture, bilateral simultaneous ruptures, ruptures repaired more than 7 days after the injury and patients that didn't give the written consent to the evaluation were excluded from this study.

All the patients referred a sudden and fierce pain in the supra patellar region and the inability to actively extend the knee.

All the lesions have been confirmed by using the US, and only in 3 cases the MRI was necessary to confirm the diagnosis (Fig. 1).

All the patients underwent surgery tendon repair with patellar drill holes technique.

All the surgeons performed the repair with the same surgical technique.

In this surgical approach the patient is positioned to permit at least $90^{\circ}$ of knee flexion during the procedure. When the tourniquet was used (by choice of the operating surgeon) it has always been deflated before the final suture of the tendon to allow complete tendons lengthen. The surgical technique entails a longitudinal midline incision from the inferior pole of the patella going proximally for 6-7 centimeters.

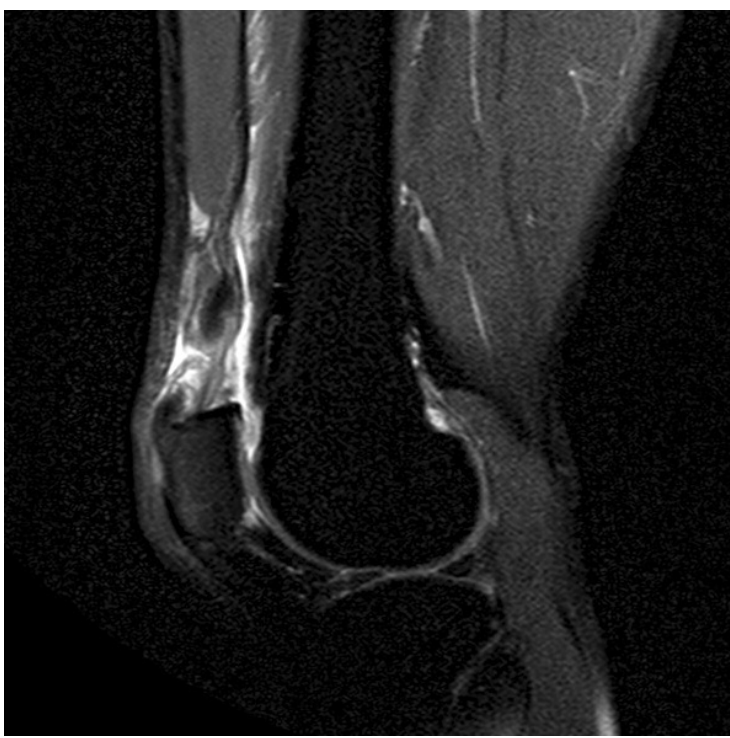

Figure 1. MR image of subcutaneous quadriceps tendon rupture.
In the proximity of the patellar surface the injured quadriceps tendon was isolated in its proximal and distal insertion (Fig. 2A).

Using absorbable suture wire (polysorb 0 Covidien@), as described by Krackow, 2 or 3 chains (depending on patella size) were made in the proximal side of the injured tendon (Figs. 2B, 3).

The second step was drilling 3 or 4 longitudinal holes, with a diameter $2 \mathrm{~K}$-wire, in the patella (Fig. 2C) and to pass the suture chains in the holes (Fig. 2D).

At this point of the procedure the tourniquet, if in use, must be deflated in order to test the tendon with func-
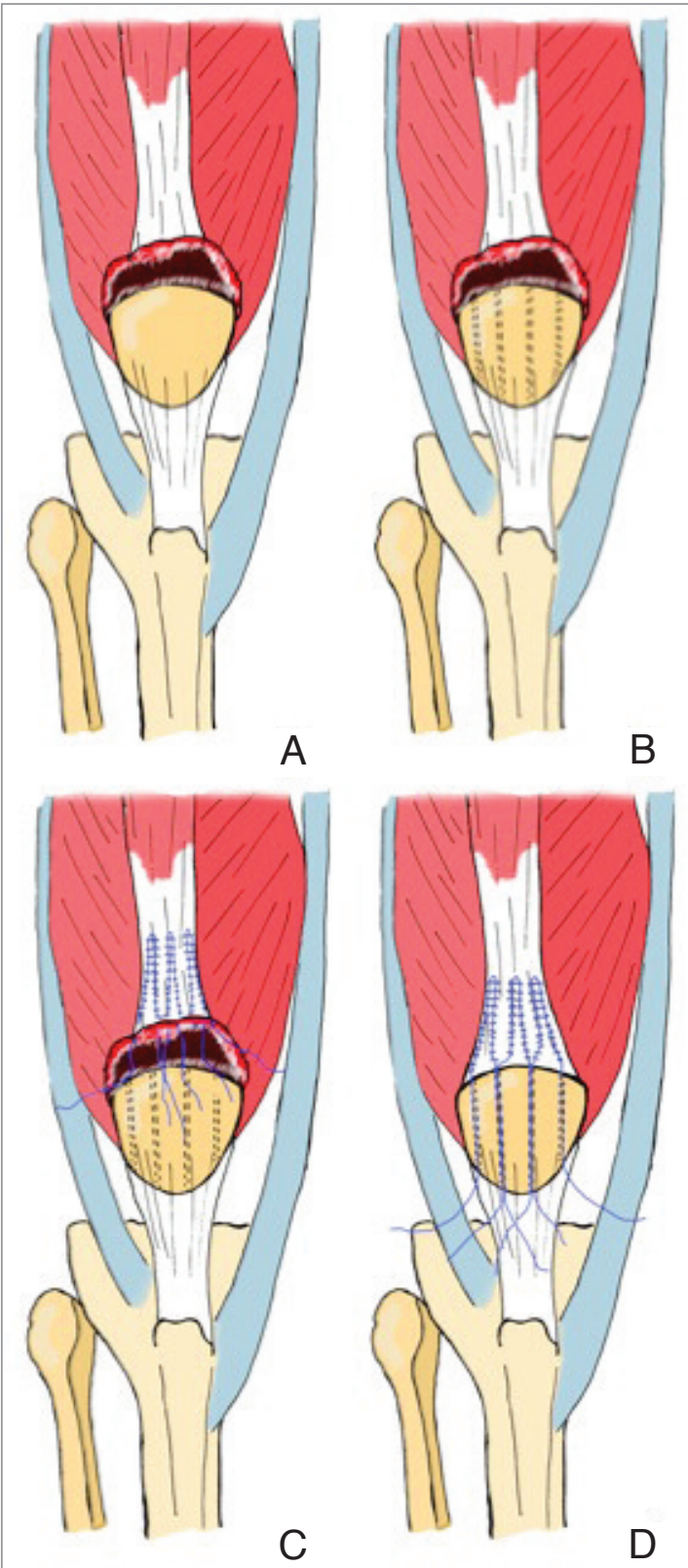

Figure 2 A-D. A. Quadriceps tendon rupture. B. Patellar drill. C. Krackow chains with absorbable wire in the proximal side of injured tendon. D. The suture chains are passed in the holes. 


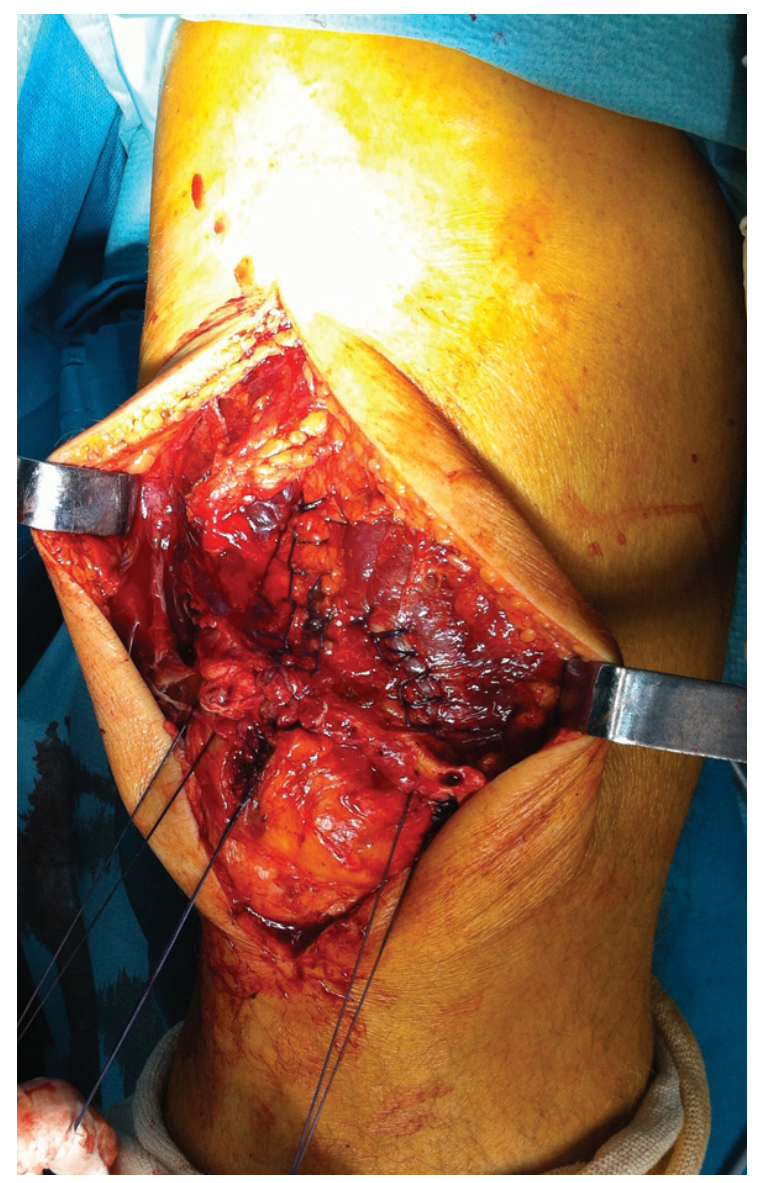

Figure 3. Intraoperative picture of suture chains.

tional tests. Tractioning distally the suture chains, the margins of the lesion must match perfectly with no anatomical gap.

The suture chains are then tied by positioning the knee in maximal extension staying as close as possible to the inferior pole of the patella.

The post-operative treatment consisted of a plaster cast in total extension and then a splint for a total of 30 days; after this period of immobilization, each patient underwent kinesis to regain complete ROM of the knee and quadriceps strength.

Each patient was evaluated studying the ROM with articular goniometer, the muscular tropism with measurements of the thigh circumferences $10 \mathrm{~cm}(10 \mathrm{C})$ and $15 \mathrm{~cm}(15 \mathrm{C})$ from the top of the patella (Fig. 4). Lysholm Score ${ }^{9}$ and Rougraff Score ${ }^{10}$ were also performed. All the patients underwent a US check, all performed by the same operator, to evaluate:

- Tendon quality;

- Quadriceps and patellar tendons thickness (comparing with contralateral);

- Tendon vascularization;

- Presence of heterotopic calcifications;

- Patellar tracking.

Predictive power of thigh circumferences at $10 \mathrm{C}$ and $15 \mathrm{C}$ far from the top of patella in terms of clinical out-

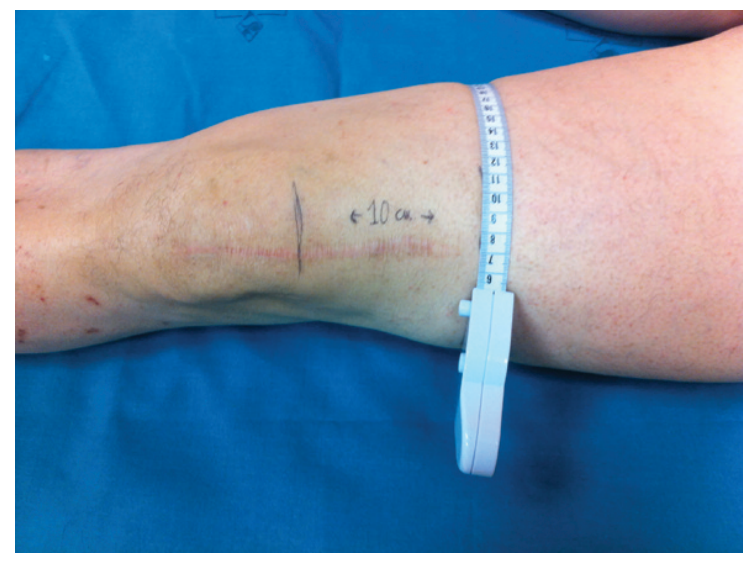

Figure 4. 10C thigh circumference measurement.

come and quality of life was investigated, comparing measurements with Lysholm and Rougraff Score with Mann-Whitney test ${ }^{11}$.

This research has been conducted according to the international standard and as required by the journal ${ }^{12}$.

\section{Results}

Mean age of patients was 54 (42-59); the affected limb was the right one in 12 cases and the left one in 8 cases. The lesion was located at the patellar insertion in 14 cases, at the middle third of the tendon in 6 cases. No ruptures in the myotendinous junction were found. The mean time from injury to surgery was 2.6 days $(+-1)$.

In all patients after the post surgical evaluation the mean active flexion was $117(+-10)^{\circ}$; the mean active extension is $1^{\circ}(+-2)$, all patients re-gained full extension except for 3 who re-gained $5^{\circ}$ and 1 that regained $10^{\circ}$. No re-ruptures were registered.

The mean difference of circumference of the quadriceps is $2.6 \%(+-1.9) 10 \mathrm{C}$ far from patella and $3.3 \%$ (+-2.1) 15C. No patients had problems of squatting after the reconstruction of the tendon (Tab. 1).

Only 1 patient complained pain and 1 complained lack of strength.

2 patients had skin healing delay. No other post-operative complications were reported.

The mean Lysholm Score calculated is 88/100 (+-9). The mean Rougraff Score is $17 / 25$ (+-2) (Tab. 1). The US indicated good healing of the repaired tendon since all of them were continuous; heterotopic ossifications were present in 18 quadriceps tendons (90\%) (Fig. 5). Structural inhomogeneity was recorded in 17 patients $(85 \%)$; vascularization was conserved in $100 \%$ of patients. Quadriceps tendon thickness was augmented in 18 cases (90\%), and the patellar tendon thickness in 5 cases $(20 \%)$.

Lateral subluxation of the patella was observed in 1 case $(0,5 \mathrm{~cm}$ of tilting in maximal flexion, absent in contralateral knee). Early patella-femoral arthritis was also observed in this case. Patellar tracking was regular in all other patients. 
Quadriceps tendon tear rupture in healthy patients treated with patellar drilling holes: clinical and ultrasonographic analysis after 36 months of follow-up

Table 1. Patients data.

\begin{tabular}{|c|c|c|c|c|c|c|c|c|c|c|c|}
\hline PATIENT & AGE & SIDE & GENDER & $\begin{array}{l}\text { FOLLOW- } \\
\text { UP }\end{array}$ & TRAUMA & $\begin{array}{l}\text { MAX } \\
\text { FLESSION }\end{array}$ & $\begin{array}{l}\text { MAX } \\
\text { ESTENSION }\end{array}$ & $10 \mathrm{C}$ & $15 \mathrm{C}$ & $\begin{array}{l}\text { LYSHOLM- } \\
\text { KNEE } \\
\text { SCORE }\end{array}$ & $\begin{array}{l}\text { ROU- } \\
\text { GRAFF } \\
\text { SCORE }\end{array}$ \\
\hline 1 & 59 & $\mathrm{R}$ & $M$ & 47 & $\begin{array}{l}\text { MOUNTAIN } \\
\text { HIKING }\end{array}$ & 110 & 0 & 2 & 3 & 89 & 6 \\
\hline 2 & 52 & $\mathrm{~L}$ & $M$ & 45 & $\begin{array}{l}\text { MOUNTAIN } \\
\text { HIKING }\end{array}$ & 100 & 0 & 0 & 3 & 86 & 11 \\
\hline 3 & 58 & $\mathrm{R}$ & $M$ & 44 & $\begin{array}{l}\text { WALKING } \\
\text { DOWNHILL }\end{array}$ & 110 & 5 & 3 & 4 & 89 & 8 \\
\hline 4 & 56 & $\mathrm{R}$ & $M$ & 47 & $\begin{array}{l}\text { ACCIDENTAL } \\
\text { FALL }\end{array}$ & 130 & 0 & 4 & 5 & 100 & 5 \\
\hline 5 & 42 & $\mathrm{R}$ & $M$ & 30 & $\begin{array}{l}\text { WALKING } \\
\text { DOWSTAIRS }\end{array}$ & 105 & 5 & 2 & 2 & 85 & 6 \\
\hline 6 & 57 & $\mathrm{R}$ & $M$ & 36 & $\begin{array}{l}\text { MOUNTAIN } \\
\text { HIKING }\end{array}$ & 120 & 0 & 1 & 2 & 89 & 8 \\
\hline 7 & 46 & $\mathrm{~L}$ & $M$ & 29 & $\begin{array}{l}\text { WALKING } \\
\text { DOWNHILL }\end{array}$ & 130 & 0 & 1 & 1 & 98 & 7 \\
\hline 8 & 57 & $\mathrm{R}$ & $M$ & 25 & $\begin{array}{l}\text { WALKING } \\
\text { DOWSTAIRS }\end{array}$ & 100 & 0 & 5 & 4 & 72 & 12 \\
\hline 9 & 53 & $\mathrm{~L}$ & $M$ & 29 & $\begin{array}{l}\text { MOUNTAIN } \\
\text { HIKING }\end{array}$ & 125 & 0 & 2 & 3 & 88 & 8 \\
\hline 10 & 55 & $\mathrm{R}$ & $M$ & 32 & $\begin{array}{l}\text { KICKING } \\
\text { AN OBJECT }\end{array}$ & 115 & 0 & 2 & 2 & 83 & 9 \\
\hline 11 & 51 & $\mathrm{R}$ & $M$ & 29 & $\begin{array}{l}\text { MOUNTAIN } \\
\text { HIKING }\end{array}$ & 115 & 0 & 6 & 9 & 77 & 12 \\
\hline 12 & 55 & $\mathrm{~L}$ & $M$ & 34 & $\begin{array}{l}\text { WALKING } \\
\text { DOWSTAIRS }\end{array}$ & 120 & 0 & 7 & 8 & 100 & 7 \\
\hline 13 & 54 & $\mathrm{~L}$ & $M$ & 29 & $\begin{array}{l}\text { WALKING } \\
\text { DOWSTAIRS }\end{array}$ & 125 & 10 & 2 & 1 & 95 & 5 \\
\hline 14 & 52 & $\mathrm{R}$ & $M$ & 32 & SKIING & 125 & 0 & 3 & 2 & 81 & 11 \\
\hline 15 & 49 & $\mathrm{R}$ & $M$ & 41 & SKIING & 130 & 0 & 1 & 2 & 100 & 7 \\
\hline 16 & 52 & $\mathrm{~L}$ & $M$ & 29 & $\begin{array}{l}\text { ACCIDENTAL } \\
\text { FALL }\end{array}$ & 105 & 5 & 4 & 3 & 79 & 10 \\
\hline 17 & 55 & $\mathrm{R}$ & $M$ & 32 & $\begin{array}{l}\text { MOUNTAIN } \\
\text { HIKING }\end{array}$ & 115 & 0 & 3 & 4 & 85 & 7 \\
\hline 18 & 58 & $\mathrm{~L}$ & $M$ & 36 & $\begin{array}{l}\text { WALKING } \\
\text { DOWNHILL }\end{array}$ & 110 & 0 & 2 & 2 & 88 & 8 \\
\hline 19 & 58 & $\mathrm{~L}$ & $M$ & 48 & $\begin{array}{l}\text { MOUNTAIN } \\
\text { HIKING }\end{array}$ & 125 & 0 & 0 & 3 & 96 & 7 \\
\hline 20 & 53 & $\mathrm{R}$ & $M$ & 42 & $\begin{array}{l}\text { KICKING AN } \\
\text { OBJECT }\end{array}$ & 130 & 0 & 1 & 3 & 74 & 9 \\
\hline
\end{tabular}

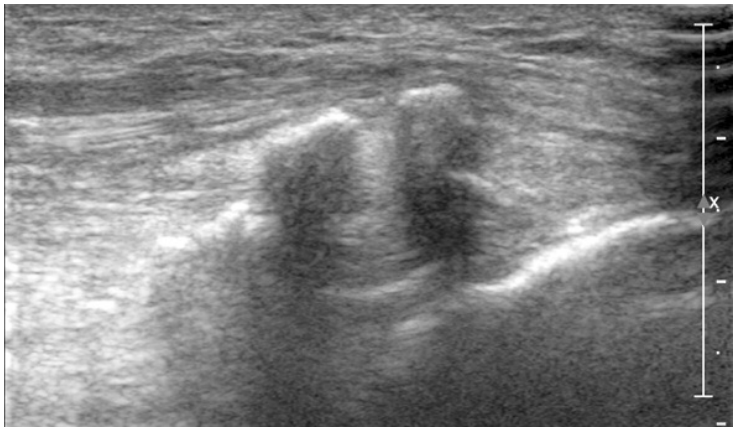

Figure 5. US view of heterotopic calcifications in repaired tendon.

\section{Statistical analysis}

Univariate analysis with Mann-Whitney test was performed to investigate the predictive power of the dif- ference in the circumference of quadriceps $10 \mathrm{C}$ and $15 \mathrm{C}$ for the clinical score and patient quality of life, measured with Lysholm and Rougraff Score.

No statistical significance has been documented with Mann-Whitney test: comparing circumference10C with Lysholm Score p: 0.312 (>0.05); 10C with Rougraff Score p: 0.904 (>0.05); 15C with Lysholm Score p: 0.521 (>0.05); 15C with Rougraff Score p: 0.473 (>0.05).

\section{Discussion}

The most represented surgical techniques for quadriceps tendon repair in acute lesions are, as reported by Ciriello et al. in his review ${ }^{13}$, simple end-to-end sutures and patellar drilling holes ${ }^{10,14-23}$. Wenzl et al. asserted that the type of repair (direct or trans-osseous suture) had no influence on the final outcome ${ }^{17}$; Puranik et al. found the best results in pa- 
tients treated with patellar drill holes, comparing with direct repair (with or without augmentation) ${ }^{15}$.

Anchors repair has recently been described by different authors ${ }^{24-26}$. Biomechanical studies were performed and showed no significant difference between anchor repair and patellar drilling holes technique ${ }^{27}$. Hart investigated biomechanical differences between trans-osseous equivalent double-row suture anchor and trans-osseous tunnel repair: he reported that both were effective in terms of strength, repair stiffness and gap formation with similar results, but the transosseous repairs were stronger ${ }^{28}$. Lighthart et al. found no significant differences in terms of displacement after 1000 cycles, adding that suture anchors are more expensive but, as confirmed also by Richards et al. ${ }^{24}$, Maniscalco et al. ${ }^{25}$ and Bushnell et al. ${ }^{26}$, allow a smaller skin incision and reduce operative times ${ }^{29}$.

For delayed repair and re-ruptures are suggested Scuderi technique ${ }^{4}$ to reinforce and Codivilla technique to lengthen the tendon. Authors agree that tendon repair in chronic ruptures gives poorer results than in acute tears $4,10,17,23$.

Our cases treated with patellar drill holes were satisfactory since the average active ROM re-gained by the patients was $1^{\circ}-117^{\circ}$. Nobody presented impairment in squatting and only one patient complained weakness. This patient had the earliest follow-up (25 months) and also presented the second highest quadriceps hypotrophy $10 \mathrm{~cm}$ proximal to the top of patella $(6 \%)$ and the highest $15 \mathrm{~cm}$ proximal $(9 \%)$. This patient had a delayed rehabilitation and was addressed to physiotherapy.

One patient only reported post-operative pain, but this patient presented also an untreated anterior cruciate ligament lesion (diagnosed 25 years prior), and we can assume he had developed both instability and ostheo-arthritis (as demonstrated by $\mathrm{x}$-rays assessment). Anyway there was no muscle hypotrophy and the patient didn't refer lack of strength; the US check indicated good healing of the treated tendon rupture.

The average Lysholm-Knee Score was 88.5/100 that is an excellent result. The average Rougraff Score of $17.1 / 25$, was excellent as well. All patients resumed their previous life style and activities.

The patient that presented lateral subluxation of the patella had the second poorest Lysholm Score (74/100); ROM was not reduced $\left(0-130^{\circ}\right)$. Kaya studied the relationship between patellar tracking and quadriceps activity, involving also the importance of balancing with hamstring ${ }^{30}$.

Statistical analysis shows no correlation between thigh circumferences of $10 \mathrm{C}$ and $15 \mathrm{C}$, that we considered as indexes of quadriceps tropism. Although without direct measurement of quadriceps strength (that was performed by other Authors ${ }^{14,10,16-19,31}$ with isokinetic and isometric tests), our findings show that thigh circumference has poor predictive power in terms of patient satisfaction and clinical outcome at mid-term follow-up.

No other works evaluated tendon's morphology after repair. The US check indicated that all the tendons examined were continuous; in 18 cases heterotypic ossifications were found. In all the tendons inhomogeneity was present; this may be because of healing and of previous degeneration. That is consistent with tendon degeneration as direct cause of rupture. Higher thickness was found in $90 \%$ of the quadriceps tendons and $25 \%$ of the patellar tendons. It's interesting to notice that the mean follow-ups of patients with this founding were respectively 46 for heterotypic ossifications and 36 for quadriceps tendon and 45 for patellar tendon thickness increase. Except for the thickening of the quadriceps tendons, affecting a high percentage of patients, the other structural changes have a higher mean follow-up compared with the total mean. Further studies may be needed to demonstrate the influence of time on quadriceps tendon and patellar restoring after surgical repair.

The population we assessed is the youngest affected by quadriceps tear rupture, since we excluded patients older than 60 that could have comorbidities or problems in practicing post-operative rehabilitation. It's interesting to observe that 7 on 20 (35\%) were mountain hiking when they got injured and 2 of them were skiing. They referred that these were their leisure activities since they were active people; 8 of our patients said that when they were younger they used to be frequent sport-player (football and tennis). This founding agrees with Shah who asserted that quadriceps tear rupture ${ }^{32}$ may affect healthy people while they're playing sport. Huberti et al. studied the connection between the degrees of flexion and the interaction of the forces between the quadriceps and the tendon of patella, observing that most of QTR occur when the knee is at semi-flexion because the tension are higher ${ }^{33}$; an elevated cycle of flexion-extension of the knee (observable in a middle-aged sportplayer) develops before and easier the limit of rupture of the tendon and histological degeneration anticipates the rupture ${ }^{34,35}$. Further epidemiological and ethiological studies should be performed to study possible relationship between sport practice, tendon degeneration and quadriceps tear rupture.

As supported by statistical analysis, patellar drilling holes technique gives satisfying results in acute lesions in terms of complete knee function and the patients' ability to resume the same regular activities pre-injury, as confirmed also by various Authors ${ }^{13,13,15-18,20-22}$ (Tab. 2). US show good healing, restoration of tendon continuity while structural changes (increase of thickness, heterotypic calcifications) (Fig. 6) are asymptomatic and do not impair function.

Limitations of this study are the lack of an objective measurement of strength with isokinetic tests and the wide range of follow-up (25-48 months).

The fact that the load tension is applied far from the site of rupture may have a role in preventing possible re-ruptures.

This is an inexpensive and non-demanding technique that if performed in acute ruptures and followed by the correct post-operative protocol, restores an acceptable knee function in subjective and objective terms. 
Quadriceps tendon tear rupture in healthy patients treated with patellar drilling holes: clinical and ultrasonographic analysis after 36 months of follow-up

Table 2. Outcomes in recent Literature.

\begin{tabular}{lllll}
\hline & NUMBER OF PATIENTS & ROM & LYSHOLM SCORE & ROUGRAFF SCORE \\
\hline RASUL JR ET AL. (1993) & 19 & $0-116^{\circ}$ & - & - \\
ROUGRAFF ET AL. (1996) & 53 & $123^{\circ}$ & - & $8.5 / 10$ \\
KONRATH ET AL. (1998) & 40 & $2-125^{\circ}$ & $87 / 100$ & - \\
O'SHEA ET AL. (2002) & 27 & $116.3^{\circ}$ & - & $22.9 / 25$ \\
DE BAERE ET AL. (2002) & 24 & $2-120^{\circ}$ & - & - \\
WENZL ET AL. & 35 & $131.8^{\circ}$ & $92.5 / 100$ & - \\
(2005) & 21 & No significant & - & - \\
RAMSEIER ET AL. (2006) & & difference with & & \\
& not affected limb & & $21.3 / 25$ \\
PURANIK ET AL. (2006) & 21 & $0.5-102.5^{\circ}$ & - & $\mathbf{1 7 / 2 5}$ \\
THE CURRENT STUDY (2014) & $\mathbf{2 0}$ & $\mathbf{1 - 1 1 7 ^ { \circ }}$ & $\mathbf{8 8 / 1 0 0}$ & \\
\hline
\end{tabular}

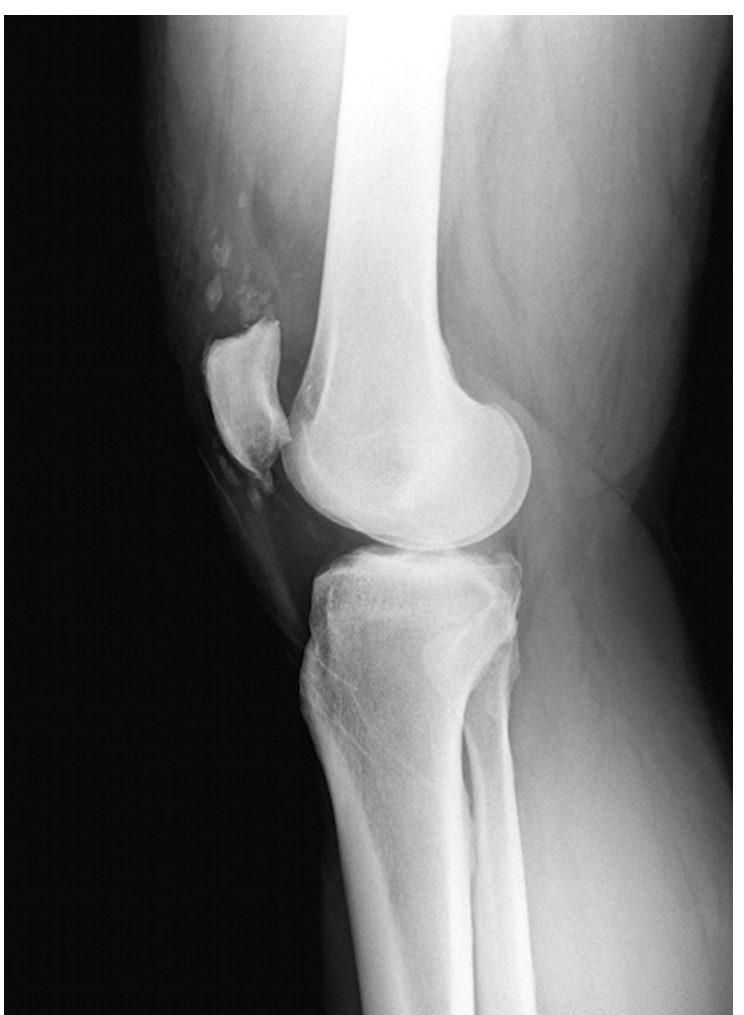

Figure 6. $\mathrm{RX}$ showing heterotopic calcifications in repaired tendon.

\section{Conclusions}

Fixation by patellar drilling holes is a reliable procedure, technically uncomplicated, straightforward to perform and inexpensive for the low hardware's costs.

According to our data the thigh circumference at a mean follow-up of 36 months is not predictive in terms of clinical outcome and quality of life.

This study is the first work that evaluates tendon morphology after surgical repair, showing a remodeling (in terms of thickness increase and presence of heterotopic calcifications) that does not influence patients' clinical outcome and quality of life.

\section{Conflict of interest}

The authors declare that they have no conflict of interest.

\section{Acknowledgment}

Paolo Schiavi (MD) for statistical analysis; Carlo Bocchi (MD) for US performing.

\section{References}

1. Clayton RA, Court-Brown CM. The epidemiology of musculoskeletal tendinous and ligamentous injuries. Injury. 2008:39:1338-1344.

2. Vidil A, Ouaknine M, Anract P, Tomeno B. Trauma-induced tears of the quadriceps tendon: 47 cases. Rev Chir Orthop. 2004;90:40-48.

3. Stern RE, Harwin SF. Spontaneous and simultaneous rupture of both quadriceps tendons. Clin Orthop Relat Res. 1980;147:188-189.

4. Scuderi C. Rupture of the quadriceps tendon: study of twenty tendon ruptures. American Journal of Surgery. 1958;95:626635.

5. Shah MK. Simultaneous bilateral rupture of quadriceps tendons: analysis of risk factors and associations. Southern Medical Journal. 2002;95:860-866.

6. Khalid $Y$, Zhanel GG. Musculoskeletal injury associated with fluoroquinolones antibiotics. Clin Plast Surg. 2005;32:495502.

7. Spector ED, Di Marcangelo MT, Jacoby JH. The radiologic diagnosis of quadriceps tendon rupture. N Eng J Med. 1995:92:590-592.

8. Ehman RL, Berquist TH. Magnetic resonance imaging of musculoskeletal trauma. Radiol Clin North Am. 1986;24(2):291319.

9. Tegner Y, Lysholm J. Rating system in the evaluation of knee ligament injuries. Clinical Orthopaedics and Related Research. 1995;198:43-48. 
10. Rougraff BT, Reeck CC, Essenmacher J. Complete quadriceps tendon rupture. Orthopaedics. 1996;16, vol 6.

11. Mann HB, Whitney DR. On a test of whether one of two random variables is stochastically larger than the other. Annals of Mathematical Statistics. 1947;18(1):50-60.

12. Padulo J, Oliva F, Frizziero A, Maffulli N. Muscles, Ligaments and Tendons Journal. Basic principles and recommendations in clinical and field science research. MLTJ. 2013;4:250-252.

13. Ciriello V, Gudipati S, Tosounidis T, Soucacos PN, Giannoudis PV. Clinical outcomes after repair of quadriceps tendon rupture: a systematic review. Injury. 2012;43(11):1931-1938.

14. O'Shea K, Kenny P, Donovan J, Condon F, McElwain JP. Outcomes following quadriceps tendon ruptures. Injury. 2002; 33:257-260.

15. Puranik GS, Faraj A. Outcome of quadriceps tendon repair. Acta Orthopaedica Belgica. 2006;72:176-178.

16. Ramseier LE, Werner CM, Heinzelmann M. Quadriceps and patellar tendon rupture. Injury. 2006;37:516-519.

17. Wenzl ME, Kirchner R, Seide K, Strametz S, Jurgens C. Quadriceps tendon ruptures - is there a complete functional restitution? Injury. 2004;35:922-926.

18. De Baere T, Geulette B, Manche E, Barras L. Functional results after surgical repair of quadriceps tendon rupture. Acta Orthopaedica Belgica. 2002;68:146-149.

19. Konrath GA, Chen D, Lock $T$, et al. Outcomes following repair of quadriceps tendon ruptures. J of Orthop Trauma. 1998;12: 273-279.

20. Rasul Jr AT, Fischer DA. Primary repair of quadriceps tendon ruptures. Results of treatment. Clin Orthop and Relat Res. 1993;289:205-207.

21. Larsen E, Lund PM. Ruptures of the extensor mechanism of the knee joint. Clinical results and patellofemoral articulation. Clin Orthop and Relat Res. 1986;213:150-153.

22. Vainionpaa S, Bostman O, Patiala H, Rokkanen P. Rupture of the quadriceps tendon. Acta Orthopaedica Scandinavica. 1985;56:433-435.

23. Siwek CW, Rao JP. Ruptures of the extensor mechanism of the knee joint. J Bone Joint Surg. 1981;63:932-937.
24. Richards DP, Barber FA. Repair of quadriceps tendon ruptures using suture anchors. Arthroscopy. 2002;18:556-559.

25. Maniscalco P, Bertone C, Rivera F, Bocchi L. A new method of repair for quadriceps tendon ruptures. A case report. Panminerva Med. 2000;42:223-225.

26. Bushnell BD, Whitener GB, Rubright JH, Creighton RA, Logel $\mathrm{KJ}$, Wood ML. The use of suture anchors to repair the ruptured quadriceps tendon. J of Orthop Trauma. 2007;21:407-413.

27. Cohen DA, Levine RG, Parks BG, Boucher HR. Suture anchor versus suture through tunnel fixation for quadriceps tendon rupture: a biomechanical study. Orthopedics. 2008;31:441.

28. Hart ND, Wallace MK, Scovell JF, Krupp RJ, Cook C, Wyland DJ. Quadriceps tendon rupture: a biomechanical comparison of transosseous equivalent double-row suture anchor versus transosseous tunnel repair. J Knee Surg. 2012;25(4):335-339.

29. Lighthart WA, Cohen DA, Levine RG, Parks BG, Boucher HR. Suture Anchor Versus Suture Through Tunnel Fixation for Quadriceps Tendon Rupture: A Biomechanical Study. Orthopaedics. 2008;31(5):441.

30. Kaya D, Doral MN, Callaghan M. How can we strengthen the quadriceps femoris in patients with patellofemoral pain syndrome? Muscles, Ligaments and Tendons Journal. 2012;2(1): 25-32.

31. West JL, Keene JS, Kaplan LD. Early motion after quadriceps and patellar tendon repairs: outcomes with single-suture augmentation. Am J of SportsMed. 2008;36:316-323.

32. Shah M, Jooma N. Simultaneous bilateral quadriceps tendon rupture while playing basketball. British Journal of Sports Medicine. 2002;36:152-153.

33. Huberti HH, Hayes WC, Stone JL, Shybut GT. Force ratios in the quadriceps and ligamentum patellae. J Orthop Res. 1984;2(1):49-54.

34. Maffulli N, Del Buono A, Spiezia F, Longo UG, Denaro V. Light microscopic histology of quadriceps tendon ruptures. Int Orthop. 2012;36:2367-2371.

35. Kannus P, Jo' zsa L. Histopathological changes preceding spontaneous rupture of a tendon. A controlled study of $891 \mathrm{pa}-$ tients. J Bone Joint Surg Am. 1991;73:1507-1525. 